\title{
Leptin, Adiponectin, and Heart Rate Variability Among Police Officers
}

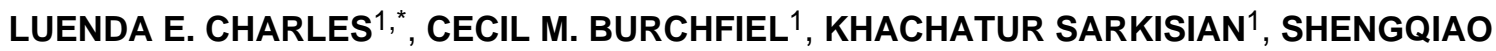 LI $^{2}$, DIANE B. MILLER ${ }^{3}$, JA K. GU ${ }^{1}$, DESTA FEKEDULEGN ${ }^{1}$, JOHN M. VIOLANTI ${ }^{4}$, and MICHAEL E. ANDREW ${ }^{1}$}

${ }^{1}$ Biostatistics and Epidemiology Branch, Health Effects Laboratory Division, National Institute for Occupational Safety and Health, Centers for Disease Control and Prevention, Morgantown, West Virginia

2University of Pittsburgh Medical Center Health Plan, Pittsburgh, Pennsylvania

${ }^{3}$ Toxicology and Molecular Biology Branch, Health Effects Laboratory Division, National Institute for Occupational Safety and Health, Centers for Disease Control and Prevention, Morgantown, West Virginia

${ }^{4}$ Department of Epidemiology and Environmental Health, School of Public Health and Health Professions, State University of New York at Buffalo, Buffalo, New York

\section{Abstract}

Objectives-Police officers have a high prevalence of cardiovascular disease (CVD). Reduced heart rate variability (HRV) is known to increase CVD risk. Leptin and adiponectin may be related to CVD health. Therefore, our objective was to investigate the relationship between these variables and HRV.

Methods-Leptin and adiponectin levels were measured in 388 officers from the Buffalo CardioMetabolic Occupational Police Stress study. HRV was assessed according to methods published by the Task Force of the European Society of Cardiology and the North American Society of Pacing Electrophysiology for measurement and analysis of HRV. Mean values of high-frequency (HF) and low-frequency (LF) HRV were compared across tertiles of leptin and adiponectin using analysis of variance and analysis of covariance; trends were assessed using linear regression models.

Results-Leptin, but not adiponectin, was significantly and inversely associated with HRV. Body mass index (BMI) and percent body fat significantly modified the association between leptin and LF (but not HF) HRV. Among officers with BMI $<25 \mathrm{~kg} / \mathrm{m}^{2}$, leptin was not significantly associated with HRV. However, among officers with BMI $\geq 25 \mathrm{~kg} / \mathrm{m}^{2}$, leptin was inversely associated with HRV, after adjustment for age, gender, and race/ethnicity; HF HRV, $P=0.019$

\footnotetext{
"Correspondence to: Luenda E. Charles, Biostatistics and Epidemiology Branch, Health Effects Laboratory Division, National Institute for Occupational Safety and Health, MS L-4050, 1095 Willowdale Rd., Morgantown, WV 26505-2888, USA. lcharles@ cdc.gov. Contract grant sponsor: National Institute for Occupational Safety and Health (NIOSH); Contract grant number: 200-2003-01580. The findings and conclusions in this article are those of the authors and do not necessarily represent the views of the National Institute for Occupational Safety and Health.
} 
and LF HRV, $P<0.0001$. Similarly, among officers with percent body fat $\geq 25.5 \%$, leptin and LF HRV showed significant, inverse associations (adjusted $P=0.001$ ).

Conclusions-Leptin levels were inversely associated with LF HRV, especially among officers with increased adiposity. Increased leptin levels may be associated with CVD-related health problems.

Adiponectin and leptin are protein hormones that are primarily secreted by adipocytes. Adiponectin has an antiinflammatory role and is generally seen as providing many health benefits (Kwon and Pessin, 2013). It stimulates fatty acid oxidation, acts on the central nervous system to influence the control of body weight, protects endothelial cells and vascular function, and regulates metabolism and insulin sensitivity (Hopkins et al., 2007; Kwon and Pessin, 2013; Swarbrick and Havel, 2008; Tabak et al., 2009). Leptin is one of the primary hormones involved in regulating energy intake and expenditure in the reproductive, renal, and cardiovascular systems (Ren, 2004) and in controlling aspects of bone remodeling (Elefteriou et al., 2005). Increased levels of leptin have been shown to be directly associated with systemic inflammation, immune-mediated disorders, and cerebrovascular and cardiovascular disease (CVD; Ble et al., 2005; Hasan-Ali et al., 2011; Liu et al., 2010; Vadacca et al., 2011). Increased leptin levels are known to adversely affect autonomic nervous system (ANS) function (Paolisso et al., 2000).

Heart rate variability (HRV) reflects the beat-to-beat variability in heart rate and the heart's ability to quickly respond to changing environments (Acharya et al., 2006). It is a noninvasive marker of the renin-angiotensin-aldo-sterone system, the cardiovascular control system, and the ANS (Rolim et al., 2013). The ANS regulates the operation of the internal organs to support the activity of the body and is composed of (a) the sympathetic nervous system, which prepares the body overall for activity, and (b) the parasympathetic nervous system, which has restorative functions such as digestion and slowing of the heartrate (Pocock and Richards, 1999). Reduced HRV has been shown to be associated with ongoing subclinical inflammation (Haensel et al., 2008), diabetes mellitus (Malpas and Maling, 1990), and an increased risk of CVD morbidity and mortality (Chandra et al., 2012; Reed et al., 2005; Tsuji et al., 1996).

Cardiovascular disease is the number one cause of morbidity and mortality in the United States (Kung et al., 2008), and studies show that police officers experience a greater burden of CVD than persons in the general population (Franke et al., 2002; Zimmerman, 2012).

Police officers also have a high prevalence of obesity (Alasagheirin et al., 2011). Because of the higher obesity and CVD prevalence, it is important to identify other factors that may be associated with subclinical CVD, such as HRV, in this occupational cohort. Levels of leptin have been shown to be associated with decreased cardiac vagal tone (Flanagan et al., 2007; Jung et al., 2012; Matsumoto et al., 2003; Paolisso et al., 2000). The relationship between adiponectin and $\mathrm{HRV}$ is less clear. In one study, adiponectin levels were not related to any HRV parameters (Jung et al., 2012). However, low levels of adiponectin were associated with cardiac sympathetic overactivity in men with Type 2 diabetes mellitus in another study (Takahashi et al., 2007). 
In their review, Elmquist et al. (1998) reported that the total absence of leptin causes morbid obesity and that leptin exerts its effects through several central nervous system pathways (Elmquist et al., 1998). A recent cross-sectional study of leptin and ANS activity found inverse associations between leptin levels and HRV after adjustment for several CVD risk factors including body mass index (BMI; Pieterse et al., 2014). This result suggests that the influence of leptin on ANS activity may not be secondary to obesity. Our study seeks to take into consideration and expand on these findings by using a detailed parameterization of HRV, available from resting data, and determining whether measures of adiposity modify associations of leptin and adiponectin with HRV. Therefore, the primary objective of this study was to investigate the association of adiponectin and leptin with HRV. Higher levels of leptin and lower levels of adiponectin are generally found in individuals with higher levels of obesity (Sztajzel et al., 2009), and women are more likely to have higher levels of obesity (Ogden et al., 2006). Therefore, secondary objectives were to determine if gender, BMI, percent body fat, and other measures of adiposity (waist circumference and abdominal height) significantly modify this association. We hypothesized that there would be an inverse association between leptin and HRV and a positive association between adiponectin and HRV. We also hypothesized that among officers with higher adiposity levels, the association between leptin and HRV would be stronger and that between adiponectin and HRV would be attenuated.

\section{METHODS}

\section{Study design and participants}

The Buffalo Cardio-Metabolic Occupational Police Stress study, a cross-sectional comprehensive examination of the health consequences of stress in law enforcement officers, began in 2004. Between June 2004 and October 2009, 710 police officers employed at the Buffalo, New York Police Department were invited to participate in this study. Data were collected at the Center for Health Research, School of Public Health and Health Professions, University at Buffalo, State University of New York (Violanti et al., 2006). The State University of New York at Buffalo and the National Institute for Occupational Safety and Health Internal Review Boards approved the study, and informed consent was obtained from all participants. Although 464 officers consented to participate, 448 officers had complete information on leptin and adiponectin levels and 447 officers completed an ECG to obtain HRV data. Of the 447 officers, those who reported having a physician-diagnosed history of irregular heart rate $(n=25)$ or had significant evidence of irregular beats or abnormal QRS intervals $(n=32)$ were excluded from these analyses, resulting in 390 officers with adequate HRV measurements. Two of these 390 officers did not have information for leptin or adiponectin. The final sample size for these crosssectional analyses of leptin and adiponectin with HRV was 388 officers, 94 women and 294 men.

\section{Clinical examination}

Each officer in this study had all measurements obtained on the same day. The officers were instructed to abstain from eating or drinking anything but water, strenuous physical exercise, and use of tobacco after 10 p.m. on the night before the day of examination. All officers 
were given a standardized breakfast of 280 calories around 8:30 a.m. after blood specimens were collected and before other components of the examination were performed.

\section{Assessment of leptin and adiponectin}

Leptin and adiponectin were analyzed using fasting serum at the University of Vermont. Adiponectin was analyzed on the Millipore Multiplex Panel A and leptin on the Millipore Multiplex Panel B. The Millipore panels use Luminex ${ }^{\circledR}$ technology. The detectable range for leptin and adiponectin is approximately 16 to $250,000 \mathrm{pg} / \mathrm{ml}$. The normal ranges, as specified by the assay manufacturers are 1,000-20,000 $\mathrm{ng} / \mathrm{ml}$ for adiponectin and 1,100$12,000 \mathrm{pg} / \mathrm{ml}$ in males and 3,800-77,000 $\mathrm{pg} / \mathrm{ml}$ in females for leptin. The interassay coefficient of variation ranges for leptin is $5.4-7.2 \%$ and for adiponectin $7.2-9.0 \%$.

\section{Assessment of HRV}

Measurement of HRV was performed according to standard methods published by the Task Force of the European Society of Cardiology and the North American Society of Pacing Electrophysiology for measurement and analysis of HRV (Camm et al., 1996). During the carotid ultrasound examination, ECG voltages were sampled at 2,000 $\mathrm{Hz}$ and captured digitally using a research quality data acquisition system designed for HRV measurement, storage, and analysis. The measurement system was provided by the Biopac Systems MP100 system/software along with an accompanying ECG Amplifier (C series), appropriate ECG leads, cables, electrodes, and a compatible PC for data processing and recording. Complete details of the assessment of HRV have been published elsewhere (Andrew et al., 2013).

\section{Assessment of covariates}

Demographic characteristics, lifestyle behaviors, and medical history and medication were obtained from all officers through self- and interviewer-administered questionnaires. Officers were asked how often they consumed alcoholic beverages with one drink defined as a 12-oz can or bottle of beer, one medium glass of wine, or one shot of liquor. The total number of drinks consumed per week was used. Officers reported their smoking status as current, former, or never. BMI was calculated as weight (in kilograms) divided by height (in meters) squared. Abdominal height was measured with the officer in the supine position. A caliper was used to measure the midsection, one inch above the iliac crests. Three measurements were taken (to the nearest $0.1 \mathrm{~cm}$ ), and the average value was used. Waist circumference was also obtained from the average of three measurements that were within $0.5 \mathrm{~cm}$ of each other. Trained and certified technicians from the Osteoporosis Research Center at the University at Buffalo measured percent body fat using the dual-energy X-ray absorptiometry (DEXA; DXA Hologic QDR 4500A machine; Hologic, Waltham, MA). The DEXA scanner uses a very low dose of radiation and also measures skeletal density, total body fat, and lean body mass. Blood pressure was determined using the average of the second and third of three separate measurements of resting systolic and diastolic blood pressure obtained with a standard sphygmomanometer.

Physical activity during the previous 7 days was obtained with the Seven-Day Physical Activity Recall questionnaire used in the Stanford Five-City Project (Sallis et al., 1985). Venous blood was drawn at the clinic during the morning hours from officers who had 
fasted for the previous $12 \mathrm{~h}$. Serum was removed from the blood after centrifugation, and aliquots were frozen at $-80^{\circ} \mathrm{C}$. Laboratory analyses of glucose and lipids were measured by standard laboratory techniques on the Beckman Coulter LX20 clinical chemistry analyzer.

Metabolic syndrome was defined using the criteria from the National Cholesterol Education Program Adult Treatment Panel III guidelines that include recent modifications from the American Heart Association and the National Heart, Lung, and Blood Institute (Grundy et al., 2005). Metabolic syndrome includes five components: abdominal obesity, hypertension, reduced HDL-C, elevated triglycerides, and glucose intolerance (see definitions in Grundy et al., 2005). Officers having three or more components were considered to have metabolic syndrome. Diabetes was defined as having a fasting blood glucose level of $\geq 126 \mathrm{mg} / \mathrm{dl}$ or taking diabetic medication. Hypertension was defined as having a systolic blood pressure $\geq$ $140 \mathrm{~mm} \mathrm{Hg}$, a diastolic blood pressure of $\geq 90 \mathrm{~mm} \mathrm{Hg}$, or a self-report of physiciandiagnosed hypertension and antihypertensive treatment.

\section{Statistical methods}

Univariate analysis was used to describe characteristics of the study participants. Because of the skewed distributions, leptin and HRV were log-transformed prior to analyses, and the results were back-transformed for reporting as means and 95\% confidence intervals (CIs). Mean values of HRV were obtained across tertiles of leptin and adiponectin using analysis of variance. $P$-values for trends were obtained from linear regression analysis. A value of $P$ $<0.05$ was considered statistically significant. Variables were chosen as potential confounders and included in the multivariate models based on their roles as confounding variables in published studies or if they were significantly associated with both the independent and dependent variables in the current study. Analysis of covariance was used to examine the effect of adjustment for several covariates (age, gender, and race/ethnicity) on the relationship of leptin and adiponectin with HRV. Gender, BMI, percent body fat, waist circumference, and abdominal height were assessed for effect modification. When stratifying on variables that were significant effect modifiers, the cut points were assigned as follows: BMI $\left(25 \mathrm{~kg} / \mathrm{m}^{2}\right)$, percent body fat $(25.5 \%)$, waist circumference $(95 \mathrm{~cm})$, and abdominal height $(20 \mathrm{~cm})$. As there is not a single, clinically meaningful cut-point for each of the above variables for both genders (except for BMI), we chose cut-points that would define high and low values reasonably well for both men and women. SAS version 9.3 was used to analyze these data (SAS, 2008).

\section{RESULTS}

Descriptive statistics of all variables are presented in Table 1. The mean ( \pm SD) age of all officers was $41.7 \pm 8.0$ with a range of 21-70 years. The majority of officers were male (75.8\%) and White (78.2\%). Women had a significantly higher mean level of percent body fat when compared with men $(30.7 \% \pm 5.9 \%$ vs. $23.8 \% \pm 5.1 \%, P<0.0001)$, whereas the reverse was true for BMI, abdominal height, and waist circumference (all $P<0.0001$ ). Men had a slightly higher but nonsignificant mean level of low-frequency (LF) HRV $(P=0.217)$, whereas women had significantly higher mean levels of high-frequency (HF) HRV ( $P=$ 0.004), leptin $(P<0.001)$, and adiponectin $(P<0.001)$. 
Age-adjusted correlation coefficients and mean values for the relationship between selected characteristics and HRV were obtained (data not shown). All of the anthropometric variables, triglycerides, and insulin were inversely and significantly correlated with $\mathrm{HF}$ HRV, whereas physical activity score was positively correlated with both HF and LF HRV. Officers who were hypertensive had a significantly lower mean HRV value (both LF and $\mathrm{HF}$ ) when compared with those who were not hypertensive: $\mathrm{HF} \mathrm{HRV}=105.8,95 \% \mathrm{CI}=$ 83.7-133.6 vs. $156.8,95 \% \mathrm{CI}=138.4-177.5, P=0.004$. Officers who had metabolic syndrome also had a significantly lower mean HRV value (both LF and HF) when compared with those who did not have metabolic syndrome: $\mathrm{HF} \mathrm{HRV}=101.9,95 \% \mathrm{CI}=8.5-125.9$ vs. $159.8,95 \% \mathrm{CI}=141.0-181.1, P<0.001$.

The associations of selected characteristics with leptin and adiponectin were also assessed, and the results are shown in Table 2. All of the anthropometric variables, total cholesterol, insulin, and HOMA were positively and significantly correlated with leptin. Officers who were hypertensive and those who had metabolic syndrome had significantly higher mean levels of leptin when compared with those who did not have either of those conditions. Age and HDL cholesterol were positively and significantly correlated with adiponectin. In contrast, all of the anthropometric variables, triglycerides, glucose, and insulin showed significant, inverse correlations with adiponectin. Officers who were hypertensive or had metabolic syndrome had significantly lower mean levels of adiponectin when compared with those who did not have either of those conditions.

In Table 3, the mean values and 95\% CIs of both HF and LF HRV are compared across tertiles of leptin. After adjustment for age, gender, and race/ethnicity, the associations between leptin and both HF HRV and LF HRV were inversely, statistically significant, $P=$ 0.028 and 0.001 , respectively. The associations between adiponectin and HRV were not significant, and thus, these results were not shown in the tables.

Gender did not modify the association between leptin and HRV, but BMI significantly modified the association between leptin and LF HRV, interaction $P=0.002$. In Table 4, the mean values and $95 \%$ CIs of HRV are compared across tertiles of leptin while stratifying by BMI. Among officers with BMI $<25 \mathrm{~kg} / \mathrm{m}^{2}$, the association between leptin and $\mathrm{HRV}$ was not significant. However, among officers with BMI $\geq 25 \mathrm{~kg} / \mathrm{m}^{2}$, the association between leptin and HRV was statistically significant. As leptin levels increased, mean values of HF and LF HRV decreased after adjustment for age, gender, and race/ethnicity; HF HRV, $P=$ 0.019 , and LF HRV, $P<0.0001$.

In Table 5, the mean values and 95\% CIs of HRV are compared across tertiles of leptin, stratified by percent body fat. Percent body fat significantly modified the association between leptin and LF HRV, interaction $P=0.010$. The results were similar to those observed with the BMI-stratified analyses. Among officers with $\pm 25.5 \%$ body fat, the association between leptin and HRV was not significant. However, among officers with $\geq 25.5 \%$ body fat, leptin was inversely related to LF HRV (but not HF HRV). Before riskfactor adjustment, strong, monotonic trends were observed, $P<0.001$, and the association was only slightly attenuated after adjustment for age, gender, and race/ethnicity, $P=0.001$. 
Waist circumference and abdominal height also significantly modified the association between leptin and LF HRV, interaction $P=0.015$ and 0.005 , respectively. The results mirrored those presented in Tables 4 and 5, and thus, these data are not shown. Leptin was significantly and inversely associated with LF HRV but not HF HRV, among officers with higher levels of central adiposity. These results showed very little attenuation after adjustment for age, gender, and race/ethnicity.

\section{DISCUSSION}

The goals of this cross-sectional study were to investigate associations of leptin and adiponectin with HRV. In this cohort of law enforcement officers, leptin levels were inversely and significantly associated with LF HRV among all officers, and particularly among officers with BMI $\geq 25 \mathrm{~kg} / \mathrm{m}^{2}$, percent body fat $\geq 25.5 \%$, and higher levels of abdominal adiposity. The associations between leptin and HRV did not differ significantly by gender.

We identified several studies that investigated the direct association between leptin and HRV and other studies that assessed the association between obesity and HRV, as it has been long established that leptin is directly related to body weight (Frederich et al., 1995; Matsumoto et al., 2003). Results on the relationship between leptin and HRV were mixed. Sztajzel et al. (2009) investigated the alterations of cardiac autonomic function in groups of patients with various levels of BMI. Their results showed that leptin was negatively correlated with most HRV indices with the exception of HF HRV. In addition, LF HRV was lower in both obese and morbidly obese patients, whereas HF HRV was lower only in morbidly obese patients, when compared with persons of normal weight. Investigators who studied autonomic function in obese and nonobese individuals reported lower HRV values in the obese participants when compared with those who were not obese and negative associations between weight and HRV (Matsumoto et al., 2003; Petretta et al., 1995; Piccirillo et al., 1996). A recently published study conducted on the same cohort of officers as our study reported inverse associations between central adiposity and HRV (Andrew et al., 2013). Another study reported lower expressions of HRV with greater abdominal-toperipheral body fat distribution and greater total adiposity (Christou et al., 2004).

Our results with leptin were not consistent with other studies. Flanagan et al. (2007) reported significant, positive correlations between leptin and LF (but not HF) HRV among healthy young women; however, these correlations were not significant among men. In a study of nonobese, nonsmoking, normotensive young Italian males, LF HRV progressively and significantly increased from the first to the fourth quartile of leptin, whereas HF HRV showed a significant decline (Paolisso et al., 2000). Among obese and nonobese males with acute myocardial infarction, leptin was positively and significantly associated with LF HRV, whereas the association with HF HRV was not statistically significant (Piestrzeniewicz et al., 2008).

Persons who are healthier overall and have a lower BMI tend to have higher levels of adiponectin (Kwon and Pessin, 2013; Piestrzeniewicz et al., 2008; Takahashi et al., 2007). In our study, associations between adiponectin and HRV were not statistically significant 
among the officers. These findings were supported by several studies (Piestrzeniewicz et al., 2008; Sztajzel et al., 2009; Takahashi et al., 2007). In a cross-sectional study, adiponectin was not related to any HRV variables among obese and nonobese males with acute myocardial infarction (Piestrzeniewicz et al., 2008). Takahashi et al. (2007) reported that adiponectin was not significantly associated with HRV in male patients with Type 2 diabetes mellitus, although they found that hypoadiponectinemia was associated with sympathetic overactivity. No significant correlations were found between serum adiponectin and LF HRV or HF HRV in another group of patients with Type 2 diabetes (Wakabayashi and Aso, 2004).

Leptin, which is elevated in most obese individuals, stimulates the sympathetic nervous system and increases sympathetic nerve activity to several organs and glands (Eikelis et al., 2003; Haynes, 2000; Mark, 2013; Tang-Christensen et al., 1999). Moreover, the effect of leptin on sympathetic nerve activity is dose-dependent, ranging from $228 \% \pm 63 \%$ to $388 \%$ $\pm 171 \%$ at $1,000 \mu \mathrm{g} / \mathrm{kg}$ in one study (Haynes et al., 1997). Research has shown that sympathetic activity is associated with the low-frequency range $(0.04-0.15 \mathrm{~Hz})$, whereas parasympathetic activity is associated with the higher frequency range $(0.15-0.4 \mathrm{~Hz})$ of modulation frequencies of the HRV (Acharya et al., 2006). Our study revealed strong inverse associations between leptin and LF HRV, whereas the association between leptin and HF HRV was not as strong and when stratified by percent body fat, the association between leptin and HF HRV was not statistically significant. Sztajzel et al. (2009) found that the LF component of HRV was lower in both obese and morbidly obese patients, whereas the HF component was lower only in morbidly obese patients, when compared with controls. Leptin also negatively correlated with most HRV indices with the exception of HF. Persons with higher levels of obesity have higher levels of serum leptin, which may explain why stronger associations were observed among officers in our study who had higher levels of overall and abdominal obesity. In our cohort, it appears that sympathetic nervous system function is more likely to be disturbed; however, specifically designed research is necessary to determine whether the association with leptin is differentially associated with sympathetic versus parasympathetic function.

Limitations include the cross-sectional design of this study that limits determination of the chronological sequence of the main variables and inference about causality. Our study also has several strengths. To our knowledge, this is one of very few studies to investigate the association of leptin and adiponectin with HRV. An accredited research laboratory performed standardized analyses of leptin and adiponectin. HRV was assessed by technicians who had expertise in the procedure, and this was done in a standardized manner. HRV measurements are easy to perform, noninvasive, and have good reproducibility, if used under standardized conditions (Kleiger et al., 1991). The sample size was adequate to perform stratified analyses, and many variables were available for assessment as confounders. The results of this study may be generalizable to police officers who work in similar environments and organizational structures like the Buffalo Police Department. 


\section{CONCLUSION}

In summary, leptin levels were inversely and significantly associated with LF HRV among all officers, and particularly among officers with BMI $\pm 25 \mathrm{~kg} / \mathrm{m}^{2}$, percent body fat $\geq$ $25.5 \%$, and higher levels of abdominal adiposity. The prevalence of obesity is increasing among the US population (Ogden et al., 2006). Officers should be educated as to the health implications of obesity, which includes higher leptin levels and reduced HRV leading to a greater risk of CVD morbidity and mortality (Lombardi, 2002). Because of the fact that a multitude of various stressors also activate the sympathetic nervous system (Brydon, 2011), the impli cation of these results is even more important in highly stressed workers such as police officers. These findings could be incorporated and emphasized in health training sessions to police officers who are exposed to a wide variety of conventional as well as unconventional stressors. Studies using prospective designs could reveal the temporal sequence of leptin and HRV. Such studies could also help us to determine whether weight gain leads to decreases in LF HRV, whether reductions in obesity measures lead to improvements in LF HRV, and/or whether decreases in leptin levels lead to improvements in LF HRV. More research is also needed to implement and evaluate interventions to reduce obesity in the workplace.

\section{LITERATURE CITED}

Acharya UR, Joseph KP, Kannathal N, Lim CM, Suri JS. Heart rate variability: a review. Med Biol Eng Comput. 2006; 44:1031-1051. [PubMed: 17111118]

Alasagheirin MH, Clark MK, Ramey SL, Grueskin EF. Body mass index misclassification of obesity among community police officers. AAOHN J. 2011; 59:469-475. [PubMed: 22017190]

Andrew ME, Shengqiao L, Wactawski-Wende J, Dorn JP, Mnatsakanova A, Charles LE, Fekedulegn D, Miller DB, Violanti JM, Burchfiel CM, Sharp DS. Adiposity, muscle, and physical activity: predictors of perturbations in heart rate variability. Am J Hum Biol. 2013; 25:370-377. [PubMed: 23564378]

Ble A, Windham BG, Bandinelli S, Taub DD, Volpato S, Bartali B, Tracy RP, Guralnik JM, Ferrucci L. Relation of plasma leptin to C-reactive protein in older adults (from the Invecchiare nel Chianti study). Am J Cardiol. 2005; 96:991-995. [PubMed: 16188530]

Brydon L. Adiposity, leptin and stress reactivity in humans. Biol Psychol. 2011; 86:114-120. [PubMed: 20193730]

Camm AJ, Malik M, Bigger JT, Breithardt G, Cerutti S, Cohen RJ, Coumel P, Fallen EL, Kennedy HL, Kleiger RE, Lombardi F, Malliani A, Moss AJ, Rottman JN, Schmidt G, Schwartz PJ, Singer DH. Heart rate variability: standards of measurement, physiological interpretation and clinical use. Task Force of the European Society of Cardiology and the North American Society of Pacing and Electrophysiology. Circulation. 1996; 93:1043-1065. [PubMed: 8598068]

Chandra P, Sands RL, Gillespie BW, Levin NW, Kotanko P, Kiser M, Finkelstein F, Hinderliter A, Pop-Busui R, Rajagopalan S, Saran R. Predictors of heart rate variability and its prognostic significance in chronic kidney disease. Nephrol Dial Transplant. 2012; 27:700-709. [PubMed: 21765187]

Christou DD, Jones PP, Pimentel AE, Seals DR. Increased abdominal-to-peripheral fat distribution contributes to altered autonomic-circulatory control with human aging. Am J Physiol Heart Circ Physiol. 2004; 287:H1530-H1537. [PubMed: 15178547]

Eikelis N, Schlaich M, Aggarwal A, Kaye D, Esler M. Interactions between leptin and the human sympathetic nervous system. Hypertension. 2003; 41:1072-1079. [PubMed: 12668587]

Elefteriou F, Ahn JD, Takeda S, Starbuck M, Yang X, Liu X, Kondo H, Richards WG, Bannon TW, Noda M, Clement K, Vaisse C, Karsenty G. Leptin regulation of bone resorption by the sympathetic nervous system and CART. Nature. 2005; 434:514-520. [PubMed: 15724149] 
Elmquist JK, Maratos-Flier E, Saper CB, Flier JS. Unraveling the central nervous system pathways underlying responses to leptin. Nat Neurosci. 1998; 1:445-450. [PubMed: 10196541]

Flanagan DE, Vaile JC, Petley GW, Phillips DI, Godsland IF, Owens P, Moore VM, Cockington RA, Robinson JS. Gender differences in the relationship between leptin, insulin resistance and the autonomic nervous system. Regul Pept. 2007; 140:37-42. [PubMed: 17187873]

Franke WD, Ramey SL, Shelley MC II. Relationship between cardiovascular disease morbidity, risk factors, and stress in a law enforcement cohort. J Occup Environ Med. 2002; 44:1182-1189. [PubMed: 12500462]

Frederich RC, Hamann A, Anderson S, Lollmann B, Lowell BB, Flier JS. Leptin levels reflect body lipid content in mice: evidence for diet-induced resistance to leptin action. Nat Med. 1995; 1:1311-1314. [PubMed: 7489415]

Grundy SM, Cleeman JI, Daniels SR, Donato KA, Eckel RH, Franklin BA, Gordon DJ, Krauss RM, Savage PJ, Smith SC Jr, Spertus JA, Costa F. Diagnosis and management of the metabolic syndrome: an American Heart Association/National Heart, Lung, and Blood Institute Scientific Statement. Circulation. 2005; 112:2735-2752. [PubMed: 16157765]

Haensel A, Mills PJ, Nelesen RA, Ziegler MG, Dimsdale JE. The relationship between heart rate variability and inflammatory markers in cardiovascular diseases. Psychoneuroendocrinology. 2008; 33:1305-1312. [PubMed: 18819754]

Hasan-Ali H, Abd El-Mottaleb NA, Hamed HB, Abd-Elsayed A. Serum adiponectin and leptin as predictors of the presence and degree of coronary atherosclerosis. Coron Artery Dis. 2011; 22:264-269. [PubMed: 21383620]

Haynes WG. Interaction between leptin and sympathetic nervous system in hypertension. Curr Hypertens Rep. 2000; 2:311-318. [PubMed: 10981165]

Haynes WG, Morgan DA, Walsh SA, Mark AL, Sivitz WI. Receptor-mediated regional sympathetic nerve activation by leptin. J Clin Invest. 1997; 100:270-278. [PubMed: 9218503]

Hopkins TA, Ouchi N, Shibata R, Walsh K. Adiponectin actions in the cardiovascular system. Cardiovasc Res. 2007; 74:11-18. [PubMed: 17140553]

Jung CH, Kim BY, Kim CH, Kang SK, Jung SH, Mok JO. Association of serum adipocytokine levels with cardiac autonomic neuropathy in type 2 diabetic patients. Cardiovasc Diabetol. 2012; 11:24. [PubMed: 22413919]

Kleiger RE, Bigger JT, Bosner MS, Chung MK, Cook JR, Rolnitzky LM, Steinman R, Fleiss JL. Stability over time of variables measuring heart rate variability in normal subjects. Am J Cardiol. 1991; 68:626-630. [PubMed: 1877480]

Kung HC, Hoyert DL, Xu J, Murphy SL. Deaths: final data for 2005. Natl Vital Stat Rep. 2008; 56:1120. [PubMed: 18512336]

Kwon H, Pessin JE. Adipokines mediate inflammation and insulin resistance. Front Endocrinol. 2013; 4:71.

Liu J, Butler KR, Buxbaum SG, Sung JH, Campbell BW, Taylor HA. Leptinemia and its association with stroke and coronary heart disease in the Jackson Heart Study. Clin Endocrinol. 2010; 72:3237.

Lombardi F. Clinical implications of present physiological understanding of HRV components. Cardiac Electrophysiol Rev. 2002; 6:245-249.

Malpas SC, Maling TJ. Heart-rate variability and cardiac autonomic function in diabetes. Diabetes. 1990; 39:1177-1181. [PubMed: 2210071]

Mark AL. Selective leptin resistance revisited. Am J Physiol Regul Integr Comp Physiol. 2013; 305:R566-R581. [PubMed: 23883674]

Matsumoto T, Miyatsuji A, Miyawaki T, Yanagimoto Y, Moritani T. Potential association between endogenous leptin and sympatho-vagal activities in young obese Japanese women. Am J Hum Biol. 2003; 15:8-15. [PubMed: 12552573]

Ogden CL, Carroll MD, Curtin LR, McDowell MA, Tabak CJ, Flegal KM. Prevalence of overweight and obesity in the United States, 1999-2004. JAMA. 2006; 295:1549-1555. [PubMed: 16595758]

Paolisso G, Manzella D, Montano N, Gambardella A, Varricchio M. Plasma leptin concentrations and cardiac autonomic nervous system in healthy subjects with different body weights. J Clin Endocrinol Metab. 2000; 85:1810-1814. [PubMed: 10843157] 
Petretta M, Bonaduce D, de Filippo E, Mureddu GF, Scalfi L, Marciano F, Bianchi V, Salemme L, de Simone G, Contaldo F. Assessment of cardiac autonomic control by heart period variability in patients with early-onset familial obesity. Eur J Clin Invest. 1995; 25:826-832. [PubMed: 8582447]

Piccirillo G, Vetta F, Fimognari FL, Ronzoni S, Lama J, Cacciafesta M, Marigliano V. Power spectral analysis of heart rate variability in obese subjects: evidence of decreased cardiac sympathetic responsiveness. Int J Obes Relat Metab Disord. 1996; 20:825-829. [PubMed: 8880349]

Piestrzeniewicz K, Luczak K, Lelonek M, Wranicz JK, Goch JH. Obesity and heart rate variability in men with myocardial infarction. Cardiol J. 2008; 15:43-49. [PubMed: 18651384]

Pieterse C, Schutte R, Schutte AE. Autonomic activity and leptin in Africans and Whites: the SABPA study. J Hypertens. 2014; 32:826-833. [PubMed: 24509121]

Pocock, G.; Richards, C. Human physiology: the basis of medicine. Oxford University Press; New York, NY: 1999. p. 171-180.

Reed MJ, Robertson CE, Addison PS. Heart rate variability measurements and the prediction of ventricular arrhythmias. QJM. 2005; 98:87-95. [PubMed: 15671474]

Ren J. Leptin and hyperleptinemia — from friend to foe for cardiovascular function. J Endocrinol. 2004; 181:1-10. [PubMed: 15072562]

Rolim LC, de Souza JS, Dib SA. Tests for early diagnosis of cardiovascular autonomic neuropathy: critical analysis and relevance. Front Endocrinol. 2013; 4:173.

Sallis JF, Haskell WL, Wood PD, Fortmann SP, Rogers T, Blair SN, Paffenbarger RS Jr. Physical activity assessment methodology in the Five-City Project. Am J Epidemiol. 1985; 121:91-106. [PubMed: 3964995]

SAS. SAS/STAT 9.2 User's guide. SAS Institute; Cary, NC: 2008.

Swarbrick MM, Havel PJ. Physiological, pharmacological, and nutritional regulation of circulating adiponectin concentrations in humans. Metab Syndr Relat Disord. 2008; 6:87-102. [PubMed: 18510434]

Sztajzel J, Golay A, Makoundou V, Lehmann TN, Barthassat V, Sievert K, Pataky Z, Assimacopoulos-Jeannet F, Bobbioni-Harsch E. Impact of body fat mass extent on cardiac autonomic alterations in women. Eur J Clin Invest. 2009; 39:649-656. [PubMed: 19490066]

Tabak AG, Brunner EJ, Miller MA, Karanam S, McTernan PG, Cappuccio FP, Witte DR. Low serum adiponectin predicts 10-year risk of type 2 diabetes and HbAlc independently of obesity, lipids, and inflammation: Whitehall II study. Horm Metab Res. 2009; 41:626-629. [PubMed: 19370507]

Takahashi N, Anan F, Nakagawa M, Yufu K, Shinohara T, Tsubone T, Goto K, Masaki T, Katsuragi I, Tanaka K, Kakuma T, Hara M, Saikawa T, Yoshimatsu H. Hypoadiponectinemia in type 2 diabetes mellitus in men is associated with sympathetic overactivity as evaluated by cardiac 123Imetaiodobenzylguanidine scintigraphy. Metabolism. 2007; 56:919-924. [PubMed: 17570253]

Tang-Christensen M, Havel PJ, Jacobs RR, Larsen PJ, Cameron JL. Central administration of leptin inhibits food intake and activates the sympathetic nervous system in rhesus macaques. J Clin Endocrinol Metab. 1999; 84:711-717. [PubMed: 10022442]

Tsuji H, Larson MG, Venditti FJ Jr, Manders ES, Evans JC, Feldman CL, Levy D. Impact of reduced heart rate variability on risk for cardiac events. The Framingham Heart Study. Circulation. 1996; 94:2850-2855. [PubMed: 8941112]

Vadacca M, Margiotta DP, Navarini L, Afeltra A. Leptin in immunorheumatological diseases. Cell Mol Immunol. 2011; 8:203-212. [PubMed: 21399656]

Violanti JM, Burchfiel CM, Miller DB, Andrew ME, Dorn J, Wactawski-Wende J, Beighley CM, Pierino K, Joseph PN, Vena JE, Sharp DS, Trevisan M. The Buffalo Cardio-Metabolic Occupational Police Stress (BCOPS) pilot study: methods and participant characteristics. Ann Epidemiol. 2006; 16:148-156. [PubMed: 16165369]

Wakabayashi S, Aso Y. Adiponectin concentrations in sera from patients with type 2 diabetes are negatively associated with sympathovagal balance as evaluated by power spectral analysis of heart rate variation. Diabetes Care. 2004; 27:2392-2397. [PubMed: 15451906]

Zimmerman FH. Cardiovascular disease and risk factors in law enforcement personnel: a comprehensive review. Cardiol Rev. 2012; 20:159-166. [PubMed: 22314143] 


\section{TABLE 1}

Descriptive results of demographics and other characteristics by gender

\begin{tabular}{|c|c|c|c|c|}
\hline Characteristics & $\begin{array}{c}\text { All }(n=388) \\
\text { Mean } \pm \text { SD }\end{array}$ & $\begin{array}{l}\text { Women }(n=94) \\
\text { Mean } \pm \text { SD }\end{array}$ & $\begin{array}{c}\text { Men }(n=294) \\
\text { Mean } \pm \text { SD }\end{array}$ & $P$-value \\
\hline Age (years; range: $21-70$ ) & $41.7 \pm 8.0$ & $40.6 \pm 6.0$ & $42.1 \pm 8.6$ & 0.050 \\
\hline BMI $\left(\mathrm{kg} / \mathrm{m}^{2}\right)$ & $29.2 \pm 4.7$ & $26.0 \pm 4.8$ & $30.3 \pm 4.2$ & $<0.0001$ \\
\hline Abdominal height $(\mathrm{cm})$ & $20.9 \pm 3.5$ & $18.1 \pm 3.1$ & $21.7 \pm 3.1$ & $<0.0001$ \\
\hline Waist circumference $(\mathrm{cm})$ & $94.8 \pm 14.3$ & $80.5 \pm 12.2$ & $99.4 \pm 11.6$ & $<0.0001$ \\
\hline Body fat (\%) & $25.5 \pm 6.1$ & $30.7 \pm 5.9$ & $23.8 \pm 5.1$ & $<0.0001$ \\
\hline Triglycerides (mg/dl) & $137.3 \pm 133.9$ & $89.4 \pm 138.5$ & $152.3 \pm 129.1$ & $<0.0001$ \\
\hline Glucose (fasting, mg/dl) & $93.0 \pm 13.1$ & $86.7 \pm 8.3$ & $95.0 \pm 13.7$ & $<0.0001$ \\
\hline HDL cholesterol (mg/dl) & $46.4 \pm 14.8$ & $58.5 \pm 15.8$ & $42.6 \pm 12.3$ & $<0.0001$ \\
\hline Physical activity score & $21.5 \pm 18.3$ & $21.6 \pm 17.2$ & $21.4 \pm 18.7$ & 0.952 \\
\hline $\operatorname{HF} \operatorname{HRV}(\mathrm{Hz})^{a}$ & $144.0(128.2-161.7)$ & $195.0(154.0-246.9)$ & $130.6(114.5-149.1)$ & 0.004 \\
\hline $\operatorname{LF} \operatorname{HRV}(\mathrm{Hz})^{a}$ & $204.6(186.6-224.3)$ & $184.7(152.4-223.7)$ & $211.4(190.3-234.8)$ & 0.217 \\
\hline Leptin $^{a}(\mathrm{pg} / \mathrm{ml})$ & $8,196(7,351-9,139)$ & $11,592(9,609-13,983)$ & $7,336(6,451-8,343)$ & $<0.0001$ \\
\hline \multirow[t]{2}{*}{ Adiponectin (ng/ml) } & $13,392 \pm 7,321$ & $19,550 \pm 8,467$ & $11,422 \pm 5,655$ & $<0.0001$ \\
\hline & $N(\%)$ & $N(\%)$ & $N(\%)$ & \\
\hline Hypertensive & $89(23.1)$ & $17(18.1)$ & $72(24.7)$ & 0.188 \\
\hline Diabetic & $9(2.3)$ & $1(1.1)$ & $8(2.8)$ & 0.694 \\
\hline Metabolic syndrome & $102(26.5)$ & $8(8.7)$ & $94(32.1)$ & $<0.0001$ \\
\hline Race/ethnicity & & & & 0.024 \\
\hline White & $298(78.2)$ & $67(71.3)$ & $231(80.5)$ & \\
\hline African American & $76(20.0)$ & $27(28.7)$ & $49(17.1)$ & \\
\hline Hispanic & $7(1.8)$ & $0(0)$ & $7(2.4)$ & \\
\hline Education & & & & 0.015 \\
\hline$\unlhd 2$ years/GED & $40(10.4)$ & $3(3.2)$ & $37(12.7)$ & \\
\hline College $<4$ yrs & $208(54.0)$ & $58(61.7)$ & $150(51.6)$ & \\
\hline College $\geq 4 \mathrm{yrs}$ & $137(35.6)$ & $33(35.1)$ & $104(35.7)$ & \\
\hline Police rank & & & & 0.173 \\
\hline Patrol officer & $267(70.1)$ & $73(77.7)$ & $194(67.6)$ & \\
\hline Sergeant/Lieutenant/Captain & $58(15.2)$ & $10(10.6)$ & $48(16.7)$ & \\
\hline Detective/Executive/Other & $56(14.7)$ & $11(11.7)$ & $45(15.7)$ & \\
\hline Smoking status & & & & 0.036 \\
\hline Current & $59(15.4)$ & $21(22.8)$ & $38(13.0)$ & \\
\hline Former & $95(24.7)$ & $25(27.2)$ & $70(24.0)$ & \\
\hline Never & $230(59.9)$ & $46(50.0)$ & $184(63.0)$ & \\
\hline
\end{tabular}

Am J Hum Biol. Author manuscript; available in PMC 2016 January 04. 
TABLE 2

Associations of selected covariates with the metabolic markers

\begin{tabular}{|c|c|c|}
\hline & Leptin (pg/ml) & Adiponectin (ng/ml \\
\hline Age (years) & $0.049,0.334$ & $0.119,0.019$ \\
\hline BMI $\left(\mathrm{kg} / \mathrm{m}^{2}\right)$ & $0.496,<0.0001$ & $-0.328,<0.0001$ \\
\hline Abdominal height $(\mathrm{cm})$ & $0.448,<0.0001$ & $-0.329,<0.0001$ \\
\hline Waist circumference $(\mathrm{cm})$ & $0.422,<0.0001$ & $-0.363,<0.0001$ \\
\hline Body fat $(\%)$ & $0.726,<0.0001$ & $0.144,0.006$ \\
\hline Triglycerides (mg/dl) & $0.083,0.104$ & $-0.210,<0.0001$ \\
\hline Glucose (fasting, mg/dl) & $0.092,0.072$ & $-0.253,<0.0001$ \\
\hline HDL cholesterol (mg/dl) & $-0.064,0.209$ & $0.548,<0.0001$ \\
\hline Physical activity score & $-0.092,0.071$ & $0.062,0.228$ \\
\hline Insulin $(\mu \mathrm{U} / \mathrm{ml})$ & $0.450,<0.0001$ & $-0.365,<0.0001$ \\
\hline \multirow[t]{2}{*}{ Adiponectin (pg/ml) } & $-0.071,0.165$ & na \\
\hline & Mean $(95 \% \mathrm{CI})$ & Mean \pm SD \\
\hline \multicolumn{3}{|l|}{ Hypertension status } \\
\hline Hypertensive & $11,549(9,235-14,445)$ & $11,824 \pm 6,794$ \\
\hline Not hypertensive & $7,471(6,610-8,444)$ & $13,859 \pm 7,441$ \\
\hline$P$-value ${ }^{a}$ & 0.001 & 0.022 \\
\hline \multicolumn{3}{|l|}{ Diabetic status } \\
\hline Diabetic & $8,717(4,264-17,819)$ & $10,179 \pm 6,715$ \\
\hline Not diabetic & $8,260(7,394-9,228)$ & $13,399 \pm 7,255$ \\
\hline$P$-value ${ }^{a}$ & 0.884 & 0.188 \\
\hline \multicolumn{3}{|l|}{ Metabolic syndrome } \\
\hline Yes & $11,534(9,354-14,223)$ & $9,530 \pm 5,339$ \\
\hline No & $7,268(6,409-8,243)$ & $14,701 \pm 7,356$ \\
\hline$P$-value ${ }^{a}$ & $<0.001$ & $<0.0001$ \\
\hline \multicolumn{3}{|l|}{ Race/ethnicity } \\
\hline White & $7,393(6,541-8,357)$ & $14,306 \pm 7,541$ \\
\hline African American & $12,576(9,868-16,027)$ & $10,311 \pm 5,850$ \\
\hline Hispanic & $9,045(4,068-20,110)$ & $12,109 \pm 3,951$ \\
\hline$P$-value ${ }^{a}$ & 0.001 & $<0.0001$ \\
\hline \multicolumn{3}{|l|}{ Education } \\
\hline$₫ 2$ years/GED & $9,044(6,457-12,668)$ & $11,616 \pm 6,229$ \\
\hline College $<4$ yrs & $8,886(7,666-10,301)$ & $13,337 \pm 7,494$ \\
\hline College $\geq 4$ yrs & $7,294(6,080-8,751)$ & $14,014 \pm 7,377$ \\
\hline $\begin{array}{l}P \text {-value } b \text { (from } \\
\quad \text { linear contrast) }\end{array}$ & 0.270 & 0.070 \\
\hline \multicolumn{3}{|l|}{ Smoking status } \\
\hline Current & $6,992(5,294-9,235)$ & $14,871 \pm 6,898$ \\
\hline Former & $8,814(7,079-10,975)$ & $14,209 \pm 8,482$ \\
\hline
\end{tabular}




\begin{tabular}{lcc}
\hline & Leptin $(\mathbf{p g} / \mathbf{m l})$ & Adiponectin $(\mathbf{n g} / \mathbf{m l})$ \\
\hline Never & $8,304(7,213-9,561)$ & $12,635 \pm 6,880$ \\
$P$-value $^{a}$ & 0.425 & 0.049 \\
\hline
\end{tabular}

Leptin was log-transformed for analysis, and then the results were back-transformed for reporting. Results for continuous variables are Pearson's correlation coefficients and $P$-values.

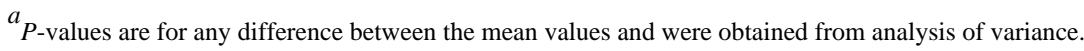

${ }^{b} P$-value is for linear trend and was obtained from analysis of variance linear contrasts. 
TABLE 3

Mean values and $95 \%$ confidence intervals (CIs) of HRV across tertiles of leptin

\begin{tabular}{ccccc}
\hline & \multicolumn{3}{c}{ Tertiles of leptin } & \\
\cline { 2 - 4 } & $\begin{array}{c}\text { First tertile } \\
\mathbf{1 6 - 5 , 7 8 1}(\boldsymbol{n = 1 2 9})\end{array}$ & $\begin{array}{c}\text { Second tertile } \\
\mathbf{5 , 8 0 6 - 1 3 , 1 2 3}(\boldsymbol{n = 1 3 0})\end{array}$ & $\begin{array}{c}\text { Third tertile } \\
\mathbf{1 3 , 1 2 8 - 9 1 , 5 8 1}(\boldsymbol{n = 1 2 9})\end{array}$ & $\boldsymbol{P}$-value \\
\hline High frequency & & & & \\
Model 1 & $172.7(141.5-210.9)$ & $148.4(121.6-181.1)$ & $116.4(95.3-142.1)$ & 0.087 \\
Model 2 & $166.4(137.9-200.7)$ & $147.4(122.3-177.6)$ & $121.7(100.8-146.8)$ & 0.144 \\
Model 3 & $172.5(142.4-209.0)$ & $149.2(124.0-179.6)$ & $112.8(93.2-136.5)$ & 0.028 \\
Low frequency & & & & \\
Model 1 & $238.9(204.4-279.2)$ & $232.2(198.8-271.3)$ & $154.1(131.9-180.2)$ & $<0.001$ \\
Model 2 & $233.3(200.8-271.1)$ & $231.2(199.2-268.4)$ & $158.5(136.4-184.2)$ & $<0.001$ \\
Model 3 & $231.9(198.4-271.2)$ & $231.2(198.8-269.0)$ & $159.4(136.4-186.2)$ & 0.001 \\
\hline
\end{tabular}

HF and LF HRV were first log-transformed for analysis, and then the results were back-transformed for reporting. $P$-values were obtained from linear regression models. Model 1: unadjusted; Model 2: adjusted for age; and Model 3: adjusted for age, gender, and race/ethnicity. 
TABLE 4

Mean values and 95\% confidence intervals (CIs) of HRV across tertiles of leptin, stratified by BMI

\begin{tabular}{|c|c|c|c|c|}
\hline & \multicolumn{3}{|c|}{ Tertiles of leptin } & \multirow[b]{2}{*}{$P$-value } \\
\hline & First tertile & Second tertile & Third tertile & \\
\hline $\mathrm{BMI}<25 \mathrm{~kg} / \mathrm{m}^{2}$ & $16-3,602(n=23)$ & $3,682-5,933(n=24)$ & $6,052-47,043(n=24)$ & \\
\hline \multicolumn{5}{|c|}{ High frequency } \\
\hline Model 1 & $150.0(97.4-231.2)$ & $221.9(145.3-338.9)$ & $191.5(125.4-292.5)$ & 0.500 \\
\hline Model 2 & $142.4(93.0-218.0)$ & $227.6(150.3-344.6)$ & $196.4(129.7-297.3)$ & 0.521 \\
\hline Model 3 & $151.2(94.3-242.6)$ & $224.0(145.1-345.9)$ & $181.2(111.6-294.3)$ & 0.918 \\
\hline \multicolumn{5}{|c|}{ Low frequency } \\
\hline Model 1 & $202.8(149.3-275.4)$ & $224.2(166.2-302.5)$ & $166.7(123.5-224.9)$ & 0.863 \\
\hline Model 2 & $200.0(146.8-272.5)$ & $225.7(167.0-305.0)$ & $167.8(124.1-226.7)$ & 0.849 \\
\hline Model 3 & $188.7(135.3-263.2)$ & $203.5(149.9-276.2)$ & $193.6(137.6-272.3)$ & 0.694 \\
\hline BMI $\geq 25 \mathrm{~kg} / \mathrm{m}^{2}$ & $105-7,021(n=105)$ & $7,189-14,684(n=106)$ & $14,701-91,581(n=106)$ & \\
\hline \multicolumn{5}{|c|}{ High frequency } \\
\hline Model 1 & $160.4(127.9-201.1)$ & $137.0(109.4-171.6)$ & $114.5(91.4-143.4)$ & 0.064 \\
\hline Model 2 & $152.7(123.8-188.4)$ & $139.8(113.5-172.2)$ & $117.7(95.6-145.1)$ & 0.120 \\
\hline Model 3 & $159.6(128.6-198.2)$ & $141.1(114.5-173.9)$ & $108.8(87.8-134.9)$ & 0.019 \\
\hline \multicolumn{5}{|c|}{ Low frequency } \\
\hline Model 1 & $261.2(218.5-312.4)$ & $227.1(190.1-271.3)$ & $148.7(124.4-177.6)$ & $<0.0001$ \\
\hline Model 2 & $252.7(213.3-299.4)$ & $230.2(194.5-272.5)$ & $151.5(128.0-179.3)$ & $<0.0001$ \\
\hline Model 3 & $253.4(212.1-302.7)$ & $232.0(195.3-275.5)$ & $151.1(126.6-180.2)$ & $<0.0001$ \\
\hline
\end{tabular}

HF and LF HRV were first log-transformed for analysis, and then the results were back-transformed for reporting. $P$-values were obtained from linear regression models. Model 1: unadjusted; Model 2: adjusted for age; and Model 3: adjusted for age, gender, and race/ethnicity. $P$-values for interaction by BMI in the association between leptin and HF HRV=0.556; leptin and LF HRV=0.002. 
TABLE 5

Mean values and 95\% confidence intervals (CIs) of HRV across tertiles of leptin, stratified by percent body fat

\begin{tabular}{ccccc}
\hline & \multicolumn{3}{c}{ Tertiles of leptin } & \\
\cline { 2 - 4 } & First tertile & Second tertile & Third tertile & P-value \\
\hline Body fat <25.5\% & $16-4,024(n=70)$ & $4,035-7,435(n=71)$ & $7,533-91,581(n=70)$ & \\
High frequency & & & & \\
Model 1 & $188.1(142.3-248.8)$ & $137.8(104.4-181.9)$ & $148.2(112.1-196.0)$ & 0.347 \\
Model 2 & $182.5(142.5-233.7)$ & $135.2(105.8-172.9)$ & $155.7(121.6-199.4)$ & 0.256 \\
Model 3 & $180.2(140.1-231.7)$ & $129.8(101.2-166.5)$ & $155.3(120.7-199.8)$ & 0.283 \\
Low frequency & & & & \\
Model 1 & $260.8(210.1-323.9)$ & $218.1(175.9-270.4)$ & $231.0(186.1-286.9)$ & 0.418 \\
Model 2 & $256.6(209.0-315.0)$ & $215.8(176.1-264.6)$ & $237.3(193.3-291.3)$ & 0.366 \\
Model 3 & $259.6(210.0-321.0)$ & $215.2(174.5-265.5)$ & $235.3(190.3-291.1)$ & 0.348 \\
Body fat 225.5\% & $784-12,277(\mathrm{n}=59)$ & $12,396-19,639(\mathrm{n}=59)$ & $20,032-73,657(\mathrm{n}=59)$ & \\
High frequency & & & & \\
Model 1 & $149.5(112.2-199.2)$ & $100.1(75.1-133.4)$ & $147.8(110.9-196.9)$ & 0.625 \\
Model 2 & $149.9(113.1-198.6)$ & $96.5(72.7-128.0)$ & $152.9(115.3-202.8)$ & 0.672 \\
Model 3 & $154.0(115.7-205.0)$ & $103.1(77.4-137.3)$ & $140.0(104.9-187.0)$ & 0.317 \\
Low frequency & & & & $<0.001$ \\
Model 1 & $216.7(172.7-272.0)$ & $171.7(136.8-215.5)$ & $138.2(110.1-173.5)$ & $<0.001$ \\
Model 2 & $217.2(173.8-271.3)$ & $166.7(133.3-208.5)$ & $142.0(113.6-177.6)$ & $<01$ \\
Model 3 & $218.4(173.4-275.1)$ & $162.2(128.7-204.3)$ & $146.0(115.7-184.3)$ & 0.001 \\
\hline
\end{tabular}

HF and LF HRV were first log-transformed, and then the results were back-transformed for reporting. $P$-values were obtained from linear regression models. Model 1: unadjusted; Model 2: adjusted for age; and Model 3: adjusted for age, gender, and race/ethnicity. $P$-value for interaction by percent body fat in the association between leptin and HF HRV=0.748; leptin and LF HRV=0.010. 